en morir tan temprano desdichado,

190 y en amar altamente venturoso;

él mismo se dio muerte de afligido;

la causa yo no sé, si Amor [no] a sido».

JOSEPH G. Fucilla

Northwestern University.

\title{
LOS "ERRORES COMUNES": PERO MEXÍA Y EL P. FEIJÓO
}

La obra toda de Feijóo está destinada a combatir los "errores comunes". Desde el prólogo del Teatro crítico se afirma esta intención: "De suerte que cada tomo, bien que el designio de impugnar errores comunes uniforme, en cuanto a las materias parecerá un riguroso misceláneo. El objeto formal será siempre uno. Los materiales precisamente han de ser muy diversos".

JUan Marichal, en su agudo ensayo intitulado "Feijóo y su papel de desengañador de las Españas", NRFH, 5 (1951), 313-323, demostró que estos "errores comunes" cumplen la misma función que las "soñadas invenciones" en la imaginación de don Quijote. Feijóo alza estos gigantes para arremeter contra ellos; los crea para poder cumplir su misión de Desengañador. Como dice el crítico citado: "El móvil literario real de Feijóo no es tanto desengañar a los españoles como explayar su personalidad por el vasto campo de los errores comunes... Su fantasía quizá, pero más aún su afán por realzar su personalidad, se recreaba con todas las creencias absurdas que él atribuía al pueblo español, pero que muchas veces sólo existían en los libros. Feijóo vio quijotescamente muchos gigantes donde no los había para poder proyectar sobre el fondo de sus sombras amenazadoras la grandiosidad señorial de su figura de Desengañador de las Españas" (p. 317).

Marichal vio, con mucho acierto, cómo Feijóo se hace a sí mismo, se proyecta en su gran creación: la de su personalidad como Desengañador de las Españas. Su estudio es el punto de partida de estas páginas, y a él remito al lector. Las premisas necesarias de que parto, en lo que atañe a Feijóo, se hallarán en su artículo.

Pero antes de intentar una nueva vía de aproximación a la actitud de Feijóo frente al Error Común, se me impone un rodeo comparativo, y espero que aclaratorio. Toda definición entraña, hasta cierto punto, una serie de comparaciones tácitas previas. Por consiguiente, como paso preliminar necesario en el asedio de Feijóo y el error común, estudiaré a grandes rasgos la actitud de un antecesor, cuya obra, en su tiempo, gozó de tanta o mayor popularidad que la del benedictino en el suyo. Me refiero a Pero Mexía y su Silva de varia lección, verdadero Teatro acrítico del siglo xvI.

Al contrario de lo que sucede con alguno de sus coetáneos (Antonio de Guevara, por ejemplo), la obra de Mexía todavía no ha sido alcanzada por el revisionismo histórico de las últimas décadas ${ }^{1}$. Sin embargo, el espigueo en sus libros ofrece algunos resultados interesantes.

1 Lo más reciente que conozco sobre el humanista sevillano son las páginas que le dedica M. Bataillon, Erasmo y España, México, 1950, t. 2, pp. 242-243, 255, y el 
Mexía, como Feijóo pero por diversas razones, tenía plena noción de la misión social del escritor y así lo asevera repetidamente². El saber acumulado en sus lecturas se pone al alcance del público, pero no discrimina entre lo cierto y lo fabuloso, ya que le interesa sólo lo curioso, con lo que su obra adquiere un marcado sabor a olla podrida, según la gráfica expresión de Bataillon. Al recolectar tan diversos materiales, Mexía cae de continuo en lo que Feijóo llamará errores comunes. Las razones de estos tropiezos nos ponen en vías de vislumbrar algo de la verdadera personalidad de Mexía.

Aunque no lo dice expresamente, colegimos de la lectura de la Silva, por ejemplo, que Mexía reconoce tres formas de adquirir conocimiento: a través de las autoridades ${ }^{3}$, por la razón ${ }^{4}$ o por la experiencia ${ }^{5}$. Nada de esto es nuevo. Ya en el siglo xiIr, para no ir más lejos, San Alberto Magno y Roger Bacon, entre otros muchos de menor categoría, habían expuesto detenidamente esta triple teoría del conocimiento; Bacon, sobre todo, con especial énfasis en la experiencia ${ }^{6}$.

A pesar de esta triple forma del conocimiento, Mexía acepta, casi sin excepción, la mayoría de los errores comunes, como la más somera lectura de los Diálogos o de la Silva patentizará. Las autoridades son repetidas ciegamente, aunque alguna vez llega a dudar de su veracidad. $\mathrm{O}$ sea que como Feijóo, pero sin nada de su insistencia, Mexía también combate algunos errores comunes. En dos ocasiones, por ejemplo, Mexía disiente de algo afirmado nada menos que por Plinio, la autoridad máxima en estas cuestiones tratadas en la Silva. La primera vez el sevillano se guía por la razón para explicar la duda de la veracidad absoluta de su fuente ${ }^{7}$; la segunda, es la experiencia la que lo hace titubear ${ }^{8}$. Pero

artículo de J. Meseguer Fernández, "Sobre el erasmismo de Pero Mexía, cronista de Carlos V", AIA, 7 (1947), 394-413. Ambos estudian su relación con Erasmo.

${ }^{2}$ En el Prohemio a la Silva, ed. Bibliófilos Españoles, Madrid, 1934, t. 1, p. 10: "Por lo cual yo, preciándome tanto de la lengua que aprendí de mis padres, como de la que me mostraron preceptores, quise dar estas vigilias a los que no entienden los libros latinos, y ellos principalmente quiero que me agradezcan este trabajo, pues son los más y los que más necesidad y deseo suelen tener de saber estas cosas". Declaración semejante prologa sus Diálogos o Coloquios.

3 "No contaré fábulas ni mentiras, sino lo que en autores aprobados he leído" (Silva, ed. cit., t. 1, p. 172).

4 "Esto que tengo dicho, más lo quise escrebir por curiosidad y ejercicio que porque lo tenga por muy verdadero, ni de tener en mucho; aunque también no va fuera de camino ni razón natural" (t. 1, p. 269).

" "Si esto es verdad (y digo si es verdad porque no lo he experimentado)..." (t. 1, p. 406 ).

"Recordemos a este respecto las palabras del Ulises dantesco, el más "moderno" de los personajes de la Divina Commedia: "De' nostri sensi... / non vogliate negar l'esperienza" (Inf., 26). Sobre el método experimental en la Edad Media es indispensable la excelente obra de LyNN THORNDike, $A$ history of magic and experimental science, en especial el segundo volumen. Sobre la época moderna es de primerísima consulta la obra de Ernst CAssirer, Das Erkenntnisproblem in der Philosophie und Wissenschaft der neueren Zeit, Berlin, 1922. El librito de Elox Bullón, Los precursores españoles de Bacon y Descartes, Salamanca, 1903, es de escasísima utilidad.

7 "Cuando Plinio afirma por cierta la cosa, todos le dan muy grande crédito, aunque en algunas partes paresce que cuenta cosas que no se tienen por verdad. Aquéllas son refiriendo y contando lo que otros dicen, y nunca dice afirmando sino cosas muy ciertas" (t. 1, pp. 175-176).

8 "Plinio lo escribe; yo no lo he experimentado ni lo afirmo" (t. 2, p. 89). 
la endeblez de su racionalismo se evidencia al pensar que si aplicamos a su obra el mismo comentario que él hace de Plinio, la invalidamos casi por completo. En cuanto a su "experimentalismo", éste se resuelve en un tópico más para discutido que para practicado ${ }^{9}$. En los hombres de ciencia medievales ocurre algo muy parecido: la experiencia en Roger Bacon o en San Alberto Magno no es método cognoscitivo independiente, como postulará el Bacon del siglo xvir, sino complementario de los otros dos y supeditado a toda suerte de factores, de ahí su falibilidad. En Mexía la experiencia se acepta con iguales limitaciones. Los siete bonetes con que se abrigaba el sabio sevillano recubrían una cabeza del mismo perfil que los experimentatores del siglo xıII. Sólo los ropajes más externos de su obra son renacentistas; quitados éstos nos hallamos con los típicos atavíos del intelectual de los siglos medios.

Muy otro es el caso de Feijóo. El Error Común pasa a ser eje de toda la obra; ésta no es acopio de curiosidades, sino búsqueda de verdades. En pleno auge del empiricismo, cuando las ciencias experimentales están levantando su vuelo de águilas, el benedictino, como forma del conocimiento, se atiene estrictamente, por lo general, a los resultados de la experiencia. Sus mejores triunfos contra el Error Común los obtiene esgrimiendo las armas incontrastables de la prueba experimental, como en el conocido caso de las florecillas de San Luis. Y cuando, por un momento, depone estas armas, Feijóo cae a plomo en lo que nosotros, a nuestra vez, clasificaríamos como Error Común; así, en el no menos conocido discurso sobre el hombre-pez de Liérganes. Éste es un caso en que, para seguir usando la terminología tradicional, el sabio benedictino deja de lado la experiencia y acepta la autoridad, en la forma de las deposiciones notariadas de los ingenuos contemporáneos del hombre-pez. En cuanto a la razón, ésta sufre las limitaciones que le impone el empirismo; así, se reduce considerablemente su influencia en el campo de las ciencias físicas.

A Mexía le bastaba con establecer lo insólito de un hecho, sin pararse a averiguar su grado de veracidad. En las pocas ocasiones en que pretende hacer esto, su esfuerzo se limita a una duda intelectual, por decirlo así, sin apurar más las cosas. La lucha contra el Error Común es algo fugaz, que pronto se desdibuja ante la acumulación de autoridades. Para Feijóo, en cambio, lo esencial es establecer si tal hecho es cierto o falso, y para ello sigue el estricto método postulado por Lord Francis Bacon y sus sucesores. El Error Común pasa, por consiguiente, a primer plano, pero, como ha hecho notar Marichal, muchos de ellos son algo facticio, creado por el mismo autor. En determinado momento hasta asistimos al proceso de gestación del Error Común, como cuando nos dice: "Puede ser que en otra ocasión, extendiéndome más sobre esta

- Dice, por ejemplo, en la Silva: "En esto la experiencia nos podría sacar de dubda, si alguno muy curioso lo quisiese hacer" (t. 1, p. 152). Comparemos esta actitud con la de don Quijote, apenas comienza su crónica, cuando decide poner a prueba la celada que acaba de manufacturar. Como es sabido, este primer intento de conocimiento a través de la experiencia tiene resultados calamitosos. Es cierto que aquí tratamos con un loco, pero el Quijote está pletórico de lances semejantes, cargados de profundo sentido. No se ha prestado atención todavía al hecho de que la obra cervantina pone en crisis las tradicionales teorías cognoscitivas. Pero éste será tema que trataré en otra ocasión. 
materia, ponga en grado de error común el axioma de que la semejanza engendra amor, como comúnmente se entiende" ("Antipatía de franceses y españoles", Teatro, II, discurso 9). Pasado cierto tiempo, y ya con la forma explícita de Error Común, esta misma idea sirve de telón de fondo al discurso sobre "Simpatía y antipatía" (Teatro, III). Lo que al principio era poco más que un rasgo de la pluma, una vibración mental, se ha corporizado ahora hasta el punto de que el benedictino puede enristrar su lanza contra él. Esta preocupación constante en la vida-obra de Feijóo con el error (existente, creado por el autor, o por crear) no creo que sea cuestión de literatura sino que, más bien, nos acerca a las formas radicales de su vivir.

Feijóo se ha hallado a sí mismo o, por mejor decir, se está creando a lo largo de su obra. Su ser se identifica con el Desengañador de las Españas que, como toda forma de vida, se va haciendo a lo largo de un determinado curso. La identificación con una personalidad específica necesita de una continua aseveración para lograr su plenitud. Quizá esto resulte más claro poniéndolo en los términos de Spinoza. El hombre es, y una vez que esto sucede se ve impelido por un consciente deseo (cupiditas) de seguir siendo de ese modo. Feijóo es el Desengañador y, por lo tanto, su cupiditas es de seguir siéndolo. Ahora bien, el Desengañador, para serlo, necesita apriorísticamente de la existencia del Engaño, afirmación perogrullesca pero inevitable: para des-engañar hay que postular, por necesidad, un engaño previo. Por consiguiente Feijóo para ser él mismo necesitaba del engaño, sin lo cual pierde todo sentido su vivir como Desengañador. Si el engaño, o error común, para volver a la terminología de Feijóo, no existía, entonces él lo inventaría ya que sin él su forma de vida quedaría vacía, y él sería un "desustanciado".

El Error Común es, pues, necesidad vital para el benedictino; sin él su ser no puede identificarse con el Desengañador. Dentro de este esquema de vida la relación que hay entre Feijóo y el Error Común es tan íntima como la que existe, digamos, entre el "yo" y "mi circunstancia" de Ortega. Feijóo sin el Error Común no podría haber sido Feijóo, sino otro. Su ser el Desengañador acarrea en forma pareja la imperiosa necesidad de crear el engaño, el error común, si es que éste no existe. El logro de su vivir, su propia mismidad, obliga a Feijóo a crear errores comunes.

The Ohio State University.

Juan Bautista Avalle-Arce

\section{XICOTÉNCATL, SÍMBOLO REPUBLICANO Y ROMANTICO}

Antes de considerar la serie de obras literarias del siglo xix inspiradas en la figura de Xicoténcatl, será conveniente hacer una rápida evocación histórica de este caudillo tlaxcalteca que opuso tenaz resistencia a Hernán Cortés cuando las tropas españolas avanzaban a la conquista de México-Tenochtitlán. Cortés y López de Gómara comparan a Tlaxcala con las repúblicas oligárquicas de Génova y Venecia ${ }^{1}$, pero el "Senado"

${ }^{1}$ Cortés, Cartas de relación, ed. P. de Gayangos, Madrid, 1866, p. 68; López DE Gómara, Historia de la conquista de México, México, 1943, t. 1, p. 184. 